\title{
$\mathrm{S}$ Turismo e
Sociedade
RevistaluFPR
}

\section{Cicloturismo em área rural do município de São Bernardo, Maranhão}

Rural cycloturism in São Bernardo, Maranhão

\author{
Rodrigo Olavo Costa Sousa ${ }^{1}$ \\ Karoliny Diniz Carvalho²
}

RESUMO: O presente estudo possui como objetivo principal analisar as contribuições do cicloturismo para o desenvolvimento da atividade turística no município de São Bernardo, Maranhão. Metodologicamente, a pesquisa caracterizou-se por uma abordagem qualitativa valendo-se da pesquisa bibliográfica de caráter exploratório e descritivo e da pesquisa de campo. Buscou-se as análises de autores como Oliveira e Anunciação (2003), Lanzillotta (2013) e Lima (2015) que entendem o cicloturismo como uma experiência turística de interpretação das áreas urbanas e naturais, sustentabilidade e valorização das comunidades. Constatou-se que no município de São Bernardo existe uma demanda de consumo das áreas naturais sob a forma de excursionismo, tanto por parte dos residentes, como por parte de visitantes em nível regional. O município possui atrativos turísticos potenciais, sobretudo nos povoados que ainda guardam elementos de ruralidade e que podem se converter em fatores de atratividade turística em longo prazo. Nesse particular, o cicloturismo pode ser uma alternativa viável

\footnotetext{
1 Bacharelado em Turismo em andamento pela Universidade Federal do Maranhão (UFMA). E-mail: rod20sousa@gmail.com

2 Mestrado em Cultura e Turismo pela Universidade Estadual de Santa Cruz (UESC). Bacharelado em Turismo pela Universidade Federal do Maranhão (UFMA). Docente do curso de Bacharelado em Turismo da UFMA - Campus São Bernardo. E-mail: karolinydiniz@gmail.com
} 
para iniciar o processo de valorização do lugar, suas memórias e paisagens e, consequentemente, ancorar perspectivas de desenvolvimento em bases locais.

Palavras-chave: Turismo; Cicloturismo; Área rural; São Bernardo; Maranhão

ABSTRACT: The present study has as main objective to analyze the contributions of bicycle tourism to the development of the tourist activity in the city of São Bernardo, Maranhão (Brazil). Methodologically, the research was characterized by a qualitative approach, drawing on exploratory and descriptive bibliographic research. It was sought the analyzes of authors such as Oliveira and Anunciação (2003), Lanzillotta (2013) and Lima (2015) who understand the cycling as a touristic experience of interpretation of urban and natural areas, sustainability and valuing communities. It was found that in São Bernardo there is a demand for consumption of natural areas in the form of excursionism, both by residents and visitors at the regional level. The municipality has potential tourist resources, especially in the villages that still retain elements of rurality and that can become factors of tourist attractiveness in a long term. In this regard, bicycle tourism can be a viable alternative in order to start the process of valuing the place, its memories and landscapes and, consequently, anchoring perspectives to development on a local basis.

Keywords: Tourism; Cycling tourism; Countryside; São Bernardo; Maranhão 


\section{INTRODUÇÃO}

O turismo de natureza abrange segmentos de mercado que promovem o aproveitamento sustentável dos atrativos naturais, a exemplo o turismo de aventura e o turismo rural. O turismo de aventura vem ganhando projeção nos contextos nacional e internacional desde a década de 1980, sendo um segmento que pode ser desenvolvido nos contextos urbanos e naturais; apresenta caraterísticas associadas ao desafio, busca do prazer, liberdade de movimento e emoção (UVINHA, 2006). Assim como os demais segmentos de turismo dito alternativos, o turismo rural propicia um contato mais próximo dos visitantes com o cotidiano do meio rural: paisagens campestres, produções agrícolas, práticas de sociabilidade, patrimônio material e simbólico (CARVALHO e MOESCH, 2013; ARENHART e FONTANA, 2019).

Uma das vivências passíveis de serem desenvolvidas nestes segmentos é o cicloturismo. O cicloturismo consiste numa atividade turística recreativa desenvolvida por meio de percursos de bicicleta em áreas urbanas ou rurais, dentro ou fora das rodovias, com interesse paisagístico, cultural ou ambiental (AGUILAR, RIVAS e GONZALEZ, 2008) agregando valor à atividade turística. O cicloturismo associa atividades de educação e interpretação ambiental em áreas livres ou protegidas, onde os ciclistas podem desenvolver uma relação particular com as áreas visitadas e comunidades. Diante desta característica, o cicloturismo vem sendo considerado como uma prática turística sustentável (LIMA, 2015).

Tendo em vista estas questões teóricas, busca-se refletir sobre o cicloturismo como atividade com potencial para impulsionar o turismo no município de São Bernardo, localizado no Estado do Maranhão. As suas caraterísticas naturais e culturais têm incentivado a realização de trilhas, rotas e eventos cicloturísticos que atraem grupos de visitantes em nível regional e estadual. As atividades relacionadas ao cicloturismo suscitam práticas de sociabilidade entre os visitantes e os moradores e de valorização do patrimônio sociocultural (SOARES, 2010).

Considerando a busca dos turistas pelo consumo de experiências e a necessidade de se promover o desenvolvimento socioeconômico integrado junto às comunidades, questiona-se: o cicloturismo cria condições para a organização dos atrativos, produtos e serviços turísticos no município de São Bernardo, Maranhão? O cicloturismo é capaz estimular a economia da zona rural?

Assim, a pesquisa possui o objetivo central de analisar as contribuições do cicloturismo para o desenvolvimento da atividade turística no município de São Bernardo, Maranhão. Como objetivos específicos buscou-se compreender a relação entre o consumo de experiências e o turismo em áreas naturais, caracterizar a atividade cicloturística, identificando os seus benefícios socioeconômicos e culturais e apontar os elementos do patrimônio socioambiental do município de São Bernardo que podem alicerçar estratégias de planejamento turístico.

Em relação aos procedimentos metodológicos, o estudo caracterizou-se por uma abordagem qualitativa valendo-se da pesquisa bibliográfica de caráter exploratório-descritivo e da pesquisa de campo (GIL, 2004). A reflexão reuniu os 
posicionamentos de Oliveira e Anunciação (2003), Lanzillotta (2013) e Lima (2015) que entendem o cicloturismo como uma experiência turística de interpretação ambiental, sustentabilidade e valorização das comunidades.

A pesquisa de campo possuiu um viés qualitativo na medida em que situou os pesquisadores no universo das práticas materiais e interpretativas que que dão visibilidade ao mundo no sentido de compreender, narrar, interpretar os fenômenos e os significados atribuídos pelos atores sociais (DENZIN e LINCOLN, 2006). Elegeu-se como técnica de coleta de dados a observação direta e sistemática dos percursos de cicloturismo realizados por grupos de visitantes na zona rural da cidade entre os meses de agosto a novembro de 2019.

A observação sistemática consiste numa "observação estruturada, planejada ou controlada, tendo como característica básica o planejamento prévio e a utilização de anotações e de controle tempo" (CERVO, 2007, p. 31). As observações ocorreram aos finais de semana, nos turnos matutino e vespertino, períodos em que os roteiros de cicloturismo são realizados com maior frequência. Utilizou-se roteiros de observação e anotações de campo com vistas a identificar as relações entre os cicloturistas, meio ambiente e comunidades e as possíveis contribuições do cicloturismo para o desenvolvimento. A análise proposta girou em torno das seguintes categorias teóricas: infraestrutura, equipamentos e serviços de apoio, atratividade dos percursos, conservação dos atrativos turísticos e políticas públicas de cicloturismo.

Para apresentar tais discussões, o artigo encontra-se dividido em seções. Inicialmente, a abordagem recai sobre o cicloturismo como uma atividade que valoriza o meio ambiente e as comunidades, sobretudo no meio rural. Então, realizase uma análise sobre a dinâmica turística do município de São Bernardo, Maranhão, enfatizando as contribuições do cicloturismo para a estruturação de um produto turístico local.

\section{CARACTERÍSTICAS E DIMENSÕES DO CICLOTURISMO}

As atividades de cicloturismo surgiram na Europa em meados do século XIX, em países como Inglaterra, França e Alemanha. Posteriormente, expandiram-se pelos Estados Unidos, destacando-se o ciclismo de estrada e a presença de clubes e associações que promovem e intensificam esta atividade (SOUZA, 2019).

No Brasil, não existem muitos registros oficiais sobre a história do cicloturismo. Somente em 1930 a bicicleta passou a se fazer presente nos espaços públicos de modo mais sistemático com a consolidação das primeiras fábricas de bicicletas no Brasil. A partir de então, popularizou-se o seu uso entre a classe trabalhadora em meados dos anos 1950. O ciclismo e o cicloturismo despontam como atividades na primeira década do século XXI incentivadas pelos planos de mobilidade urbana e pelos projetos de criação de ciclofaixas e ciclovias no contexto urbano (ROLDAN, 2000; FARIA, 2016). 
De acordo com Serrano, César e Prado (2015), os passeios ciclísticos noturnos na cidade de São Paulo deram origem ao cicloturismo no território nacional. Concomitantemente surgiram iniciativas de empreendedores que começaram a organizar os primeiros passeios, viagens e negócios atrelados a este segmento. A partir dos anos 1980, experiências de roteiros e circuitos cicloturísticos podem ser observadas no Brasil com o pioneirismo de Santa Catarina, por meio do circuito de cicloturismo do Vale Europeu, seguido dos estados de Minas Gerais, Paraná e São Paulo (FARIAS, 2019; CARVALHO RAMOS e SYDOW, 2013).

O modelo de gestão público-privado do Vale Europeu incentivou a criação de novos circuitos a partir de 2010. De acordo com o levantamento realizado por Mendonça (2017), há a concentração de roteiros na região Sul do país e um número reduzido na região Nordeste, o que representa oportunidades socioeconômicas, como por exemplo, o incentivo à cadeia produtiva da bicicleta. Destacam-se os roteiros e circuitos cicloturísticos dos estados de São Paulo, Acre, Minas Gerais, Sergipe, Rio de Janeiro, Paraíba, Santa Catarina e Paraná. Nestes últimos, situam-se as principais operadoras que atuam nesse segmento são promovidos eventos com o objetivo de atrair um público significativo de turistas (RUFINO e CRISPIM, 2015; FARIAS, 2016).

Os roteiros de cicloturismo podem ser desenvolvidos em áreas urbanas e rurais Um dos primeiros conceitos sobre cicloturismo foi proposto por Ritchie (1998, p.568569), que o definiu como "qualquer atividade realizada por aqueles que estão de férias por mais de vinte e quatro horas ou uma noite, e para quem a bicicleta é parte integral da viagem, mesmo que não a utilize em alguns momentos". Roldan (2000, p.21) por sua vez, estabelece a diferença entre ciclismo recreativo e o cicloturismo:

O Cicloturismo se diferencia do Ciclismo Recreativo no aspecto das distâncias, que são maiores, o tempo total envolvido é muito maior (não somente em horas, podendo chegar a semanas e meses), e talvez, a principal das diferenças: o planejamento. Pois, devido às "dimensões" serem maiores, passa a requerer um planejamento detalhado quanto ao roteiro, aos equipamentos, bagagem e o principal para tal: o condicionamento físico do indivíduo, compatível com sua viagem.

Outra conceituação é abordada por Aguilar, Rivas e Gonzalez (2008, p.27), os quais entendem o cicloturismo como "[...] atividade turística recreativa, que consiste em realizar percursos de bicicleta em setores urbanos ou rurais, dentro ou fora das rodovias, com interesse paisagístico, cultural ou ambiental, nas modalidades de roadbike, citybike, mountainbike, touringbike e outras".

O cicloturismo pode ser realizado de forma espontânea ou com a intermediação de agências de turismo. Por meio da articulação entre a iniciativa pública e privada são criadas as condições básicas para que a prática turística ocorra. Como exemplos, destacam-se a implantação de estruturas de apoio e a oferta de serviços de hospedagem e alimentação ao longo dos roteiros desenvolvidos.

Os passeios de bicicleta realizados ao longo do dia caracterizam a modalidade ciclolazer. À medida que os passeios de bicicleta integram uma programação 
mais ampla de viagem, que pode durar dias ou semanas, passa a ser denominado cicloviagem/cicloturismo (ROLDAN, 2000). Neste caso, a bicicleta não é vista apenas como transporte que viabiliza os deslocamentos, mas como elemento indissociável das experiências realizadas pelos visitantes.

Lima (2015) converge nesta questão ao pontuar que os cicloturistas produzem também sentidos e significados aos trajetos percorridos. Os fragmentos da memória e das narrativas orais, as paisagens adquirem significância à medida que os cicloturistas abrem caminhos para a valorização do espaço material e simbólico dos espaços visitados.

Na busca pela ampliação dos conhecimentos sobre a dinâmica do cicloturismo, Lamont (2009, p.14-25) aponta alguns elementos que auxiliam no entendimento de suas características. O autor destaca que a experiência cicloturística ocorre fora da região de moradia da pessoa, o cicloturismo pode fazer parte de uma programação mais ampla de viagem e possui um caráter não competitivo. Além disso, pedalar deve ser o principal propósito da viagem, a participação no ciclismo ocorre apenas num contexto ativo e o cicloturismo é uma forma de recreação ou lazer.

Os cicloturistas são motivados pela busca por uma relação mais próxima com a natureza, com as paisagens conservadas e com os estilos de vida dos moradores das áreas urbanas e/ou rurais. "O cicloturista [...] é explorador aventureiro, sempre em busca de novos lugares, novas culturas e de fácil convivência onde chega, e também realiza atividades, projetos junto à comunidade por onde passa" (OLIVEIRA e ANUNCIAÇÃO, 2003, p.49-50).

Além de se constituir num transporte sustentável, o uso da bicicleta para fins turísticos auxilia no bem-estar físico, psicológico e emocional dos turistas. $O$ cicloturismo desempenha um papel importante na mobilidade ativa, refletindo o desejo de liberdade e aventura (KLOS, MISKALO-CRUZ e MORAES, 2016). Ainda, segundo os autores, permite o estranhamento e a redescoberta de espaços urbanos e naturais, dos aspectos culturais dos lugares percorridos, propiciando novas conexões, afetos e sensibilidades, mesmo nos percursos cotidianos. A prática estabelece ainda novas relações entre o homem e o espaço, posto que o ritmo cadenciado entre os visitantes e as paisagens naturais e/ou culturais amplia a percepção sensorial, estimula atitudes de conservação e valorização dos ecossistemas (OLIVEIRA, 2018).

Como experiência de lazer, o cicloturismo tende a agregar valor à oferta turística de muitas comunidades, como as que se localizam no meio rural. Arenhart e Fontana (2019) assinalam que a atividade turística vem sendo apontada como alternativa econômica ao ressignificar as propriedades rurais, incentivando a pluriatividade. Ao mesmo tempo promove a melhoria dos índices de qualidade de vida local.

$\mathrm{Na}$ visão das autoras, o planejamento turístico em áreas rurais deve incorporar princípios da sustentabilidade, de modo a garantir a autonomia dos empreendedores rurais na organização dos produtos e serviços. Ainda, o acompanhamento da dinâmica turística no meio rural torna-se necessário com vistas a mitigar os efeitos 
negativos do turismo, valorizar o patrimônio e contribuir para o desenvolvimento rural sustentável.

Nesse norte, o cicloturismo alinha-se às novas propostas de experiências turísticas nas áreas naturais, abrangendo o sentido da descoberta, conexões com o meio ambiente e as comunidades. Os roteiros e rotas cicloturísticas redefinem o olhar dos visitantes sobre os destinos, dando suporte às economias locais e instituindo novas visões para o desenvolvimento local.

O cicloturismo possui a particularidade de movimentar cinco segmentos: o turismo rural, o ecoturismo, turismo de aventura, turismo cultural e gastronômico (CARVALHO, RAMOS e SYDOW, 2013). Os roteiros de cicloturismo conciliam aspectos de emoção e risco calculado, característicos do segmento de turismo de aventura (UVINHA, 2006). Paralelamente, os passeios de bicicleta promovem o intercâmbio sociocultural, a interação dos visitantes com as paisagens naturais e a cultura das comunidades. Tais aspectos aproximam o cicloturismo como atividade que pode agregar valor à oferta do turismo rural (CARVALHO e MOESCH, 2013).

O incentivo a essa modalidade pode estabelecer novas funções econômicas às áreas rurais. Os segmentos impulsionados pelo cicloturismo contribuem para a diversificação das atividades não agrícolas no meio rural, fortalecendo os aspectos de multifuncionalidade e pluriatividade que caracterizam o meio rural brasileiro contemporâneo (LANZILLOTTA, 2013).

Os roteiros de cicloturismo ampliam a permanência dos visitantes nas comunidades e o seu protagonismo na gestão da atividade turística. Associado a um planejamento integrado e responsável, eles configuram uma fonte de renda complementar para as famílias e estimulam o desenvolvimento territorial. (SERRA i SERRA, 2016; HAN, MENG e KIM, 2017).

O cicloturismo tende a dinamizar as economias dos destinos, sinalizando para o empreendedorismo comunitário, com o surgimento de negócios, de produtos e serviços de apoio aos cicloturistas. Souza (2019) enfatiza o setor de tecnologia, com a oferta de aplicativos eletrônicos com vistas ao mapeamento dos percursos. Destaca ainda as áreas de alimentação e meios de hospedagem, como os Bike hotéis, como oportunidades de negócios impulsionados por esta atividade.

No entanto, há a necessidade de políticas públicas voltadas ao desenvolvimento do cicloturismo não somente como transporte sustentável, mas também como fator de dinamização do turismo, bem-estar e qualidade de vida dos moradores e de promoção de uma imagem positiva das localidades (SALDANHA, 2017; FLORES et al., 2015). As políticas públicas de ciclomobilidade propiciam o uso de uma infraestrutura subutilizada, a combinação dos diferentes modais de transporte, além de maximizar o seu impacto econômico em nível local (MRNJAVAC, KOVACIC, e TOPOLSEK, 2014; TEIXEIRA e EDRA, 2018). Nessa direção, Saldanha (2017) argumenta, com base na literatura internacional, que o planejamento do cicloturismo envolve: 1) a análise do desempenho atual da atividade, por meio da identificação das rotas para a promoção e da existência de planos, programas e projetos de manutenção e aprimoramento 
das rotas; 2) o desenvolvimento da infraestrutura para o cicloturismo, que inclui uma rede de serviços e equipamentos de apoio; e 3) a promoção da área de destino, com o incentivo a eventos ciclísticos e desenvolvimento de rotas.

Estasfasessão interdependentese incluema preocupação comasustentabilidade econômica, ambiental e sociocultural. O referido processo pode ocorrer de maneiras distintas em cada país, seja por meio do Estado, seja pelo envolvimento e participação de comunidades, instituições não-governamentais e de empresas que atuam de forma participativa e corresponsável no planejamento e gestão dos seus produtos e serviços (SALDANHA, 2017).

As etapas de fomento ao cicloturismo dialogam com a perspectiva de Rosa e Silva (2020), ao argumentarem que uma cidade cycle friendly ou "amiga do ciclismo" possui uma gestão urbana integrada, além de normas jurídicas com o objetivo de organizar as ciclorrota/circuitos e assegurar o acolhimento aos visitantes. De acordo com as autoras, compete ao poder público a dotação de infraestrutura necessária para que os roteiros possam ser operacionalizados: sinalização turística e/ou interpretativa, mapas turísticos, segurança, infraestrutura de apoio, além de ações de promoção, sensibilização e qualificação profissional para os profissionais que atuam direta ou indiretamente com o cicloturismo.

Em conjunto, estes elementos definem a atratividade de um destino cicloturístico, conforme esquematizado na Figura 1:

FIGURA 1 - ELEMENTOS DE ATRATIVIDADE DE UM DESTINO DE CICLOTURISMO.

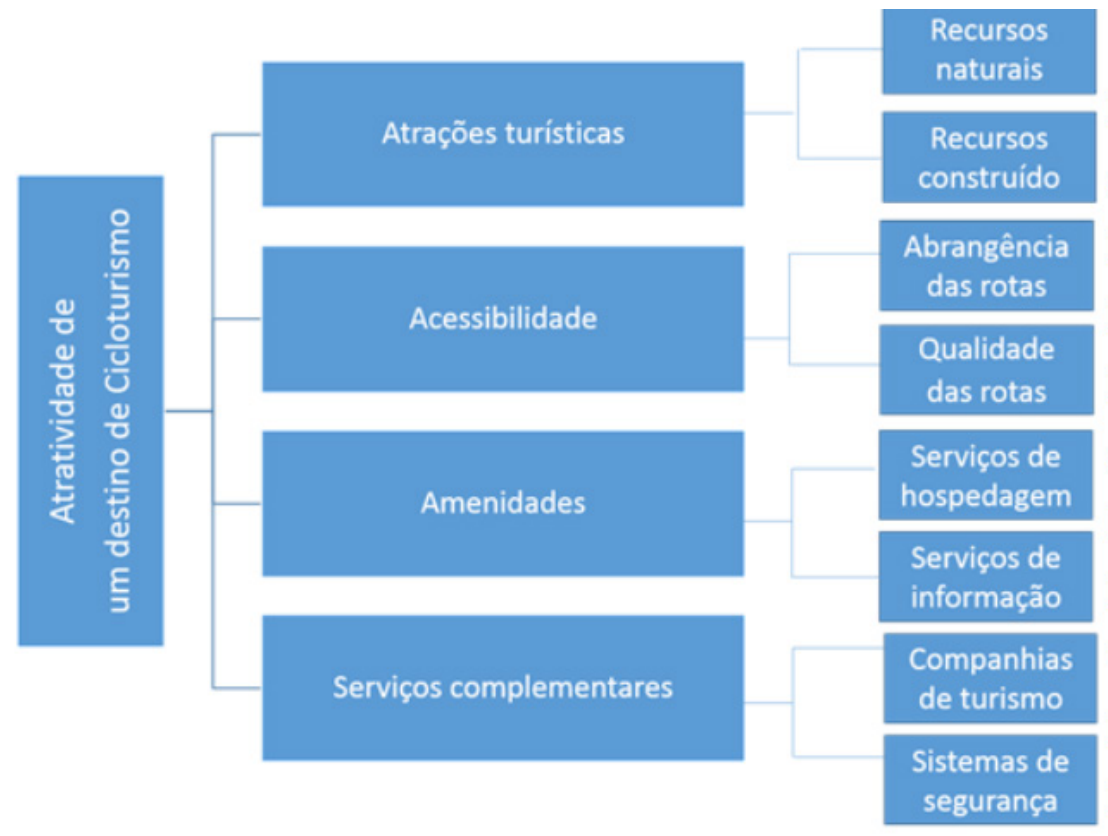

FONTE: Adaptado de Saldanha (2017, p.36). 
Desse modo, a existência de uma infraestrutura cicloviária, equipamentos e serviços de apoio garante maior autonomia e segurança ao ciclista. Em se tratando da mobilidade turística, ela permite ao visitante novas percepções sobre os lugares, possibilitando interações sociais capazes de enriquecer a sua experiência (HANDY; VAN WEE; KROESEN, 2014). No tocante às áreas onde será realizado o processo de planejamento de rotas e roteiros cicloturísticos, os estudos de viabilidade e o diagnóstico dos locais são fundamentais na medida em que identificam e caracterizam os elementos dos ecossistemas e os seus respectivos níveis de fragilidade. Além desses requisitos, o objetivo consiste em verificar as condições de acessibilidade aos diferentes perfis de público.

Após a realização do diagnóstico inicial, os gestores devem definir a capacidade de carga ambiental, elencar os bens, serviços, equipamentos e atrativos existentes, elaborar o percurso ou trajeto e identificar o grau de dificuldade do roteiro cicloturístico (FIALHO; EUSEBIO, 2017; CARVALHO, 2017). Para fins de comercialização, as estratégias de marketing promovem os roteiros como parte integrante da experiência turística de um destino (DEENIHEM e CAULFIELD, 2015).

O envolvimento dos setores públicos, empresariado e comunidade local constitui fator essencial com vistas a promover a mobilidade sustentável e a valorização dos espaços urbanos e rurais (DE OLIVEIRA NEVES; ESPERANÇA, 2011; SERRA i SERRA, 2016). O desenvolvimento socioeconômico pode ser atingido por meio de práticas solidárias entre os distintos atores sociais - governo, comunidade e cadeia produtiva do turismo - com vistas à organização dos locais de interesse turístico, à implantação de estratégias de acompanhamento das atividades turísticas e seus impactos, bem como da formação de espaços de diálogo. Dessa forma a comunidade se beneficiará do turismo em termos econômicos, sociais e culturais.

A partir desta perspectiva, este estudo volta-se para o município de São Bernardo, Maranhão, onde a demanda pelo uso de bicicleta, seja para fins utilitários ou turísticos, vem se configurando numa alternativa de consumo da área rural para fins de lazer e recreação por parte dos moradores e visitantes. Dessa forma, surgem rotas e roteiros de cicloturismo que podem gerar oportunidades sociais e econômicas nos locais onde a sua dinâmica ocorre com maior ênfase. Na próxima seção, analisase o segmento cicloturismo no município de São Bernardo, pontuando as suas contribuições para a valorização do patrimônio ambiental e cultural.

\section{A PRÁTICA CICLOTURÍSTICA NO MUNICÍPIO DE SÃO BERNARDO (MA): POR UMA VALORIZAÇÃO DAS PAISAGENS E TRADIÇÕES RURAIS}

O município de São Bernardo está localizado a $370 \mathrm{~km}$ da capital do estado do Maranhão e possui uma população de 26.480 habitantes, sendo que destes, 44,7\% residem na zona urbana e 55\% na zona rural (IBGE, 2010). Sua economia gira em torno dos setores agropecuário, indústria extrativista, setor de construção, comércio e serviços (IBGE, 2010). 
São Bernardo insere-se no território denominado Baixo Parnaíba Maranhense (Figura 2), uma área marcada por traços de ruralidade na relação entre as comunidades e meio ambiente (COSTA, 2016; BOTELHO, 2017). As práticas de produção artesanal, as narrativas orais, os processos produtivos, saberes e fazeres tradicionais, as relações de solidariedade entre os moradores durante os festejos religiosos integram o repertório sociocultural local (SOUSA, PINTO e JÚNIOR, 2018). Este retrata um sistema simbólico que se mantém apesar de iniciativas de capitalização das áreas rurais para o desenvolvimento de atividades agroexportadoras sob a égide do capital (BOTELHO, 2017).

\section{FIGURA 2- LOCALIZAÇÃO GEOGRÁFICA DOS MUNICÍPIOS DO BAIXO PARNAÍBA MARANHENSE.}
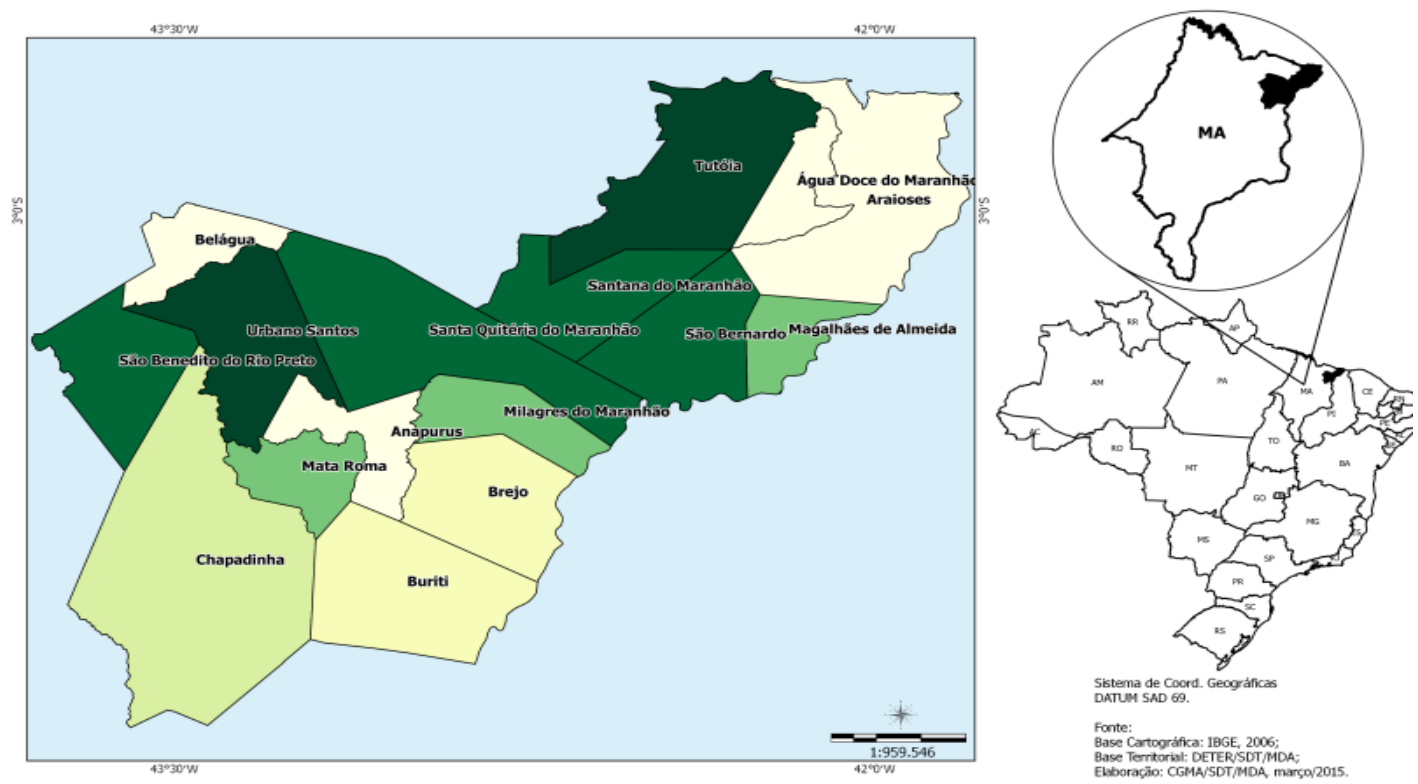

FONTE: Sistema de Informações Territoriais (2015)

No que concerne à atividade turística, o município situa-se entre dois polos turísticos maranhenses: o Polo Munim e o Polo Lençóis Maranhenses, sendo via de acesso para destinos turísticos como Parnaíba (PI) e Fortaleza (CE) (GARCÊS, 2019). Possui um potencial turístico latente, com destaque para os festejos religiosos e atrativos naturais que movimentam um público de visitantes de áreas vizinhas e estimulam a economia por meio do comércio informal de bens e serviços (INSTITUTO BRASILEIRO DE GEOGRAFIA E ESTATÍSTICA - IBGE, 2010).

O município detém atrativos naturais e um ecossistema que possibilitam atividades relacionadas ao turismo de natureza, turismo ecológico e de lazer, tais como caminhadas, trilhas, evidenciando-se práticas de excursionismo. Além disso, por se constituir num local eminentemente rural, existe um patrimônio simbólico representado pelos festejos religiosos, produção de cachaça artesanal e práticas 
tradicionais de uso e ocupação do meio rural. Tais singularidades podem originar segmentos turísticos alternativos, como o turismo rural, o agroturismo, o turismo de base comunitária e o turismo cultural, sobretudo na vertente religiosa.

O turismo é entendido como fenômeno sociocultural que propicia intercâmbios materiais e simbólicos. A busca pela singularidade dos patrimônios ambientais e culturais dos destinos consiste num dos principais fatores de mobilidade turística. Tendo esta perspectiva em vista, Irving e Azevedo (2002) acentuam que:

O turismo, por sua natureza e essência, implica a busca de diferenças que são traçadas pela cultura e pelo patrimônio. Ao representar um dos veículos mais importantes de divulgação cultural, o turismo emerge como instrumento de reafirmação de culturas e de patrimônios singulares. Esta atividade tem, na cultura e no patrimônio, esteios relevantes que Ihe permitem promover encontros de singularidades (IRVING e AZEVEDO, 2002, p. 133).

Nos últimos anos, assiste-se ao movimento espontâneo de grupos de ciclistas amadores e profissionais de São Bernardo e de outros municípios em direção aos povoados Baixa Grande, Boa Esperança, Currais e São Raimundo, dentre outros. As características geográficas deste território são propícias à organização de passeios e roteiros intermunicipais de bicicleta e à realização de eventos cicloturísticos de caráter regional, como competições de pequeno e médio porte, promovidos por iniciativas particulares em articulação com o poder público local.

No que concerne às características geomorfológicas e pelo fato do Estado do Maranhão estar situado numa área de transição, encontram-se diversos tipos de vegetação: o cerrado, a caatinga e a floresta estacional perenifólia (SISTEMA DE INFORMAÇÕES TERRITORIAIS, 2015). O clima característico do município de São Bernardo é sub-úmido seco (MDA, SDT, 2005). Neste tipo, as temperaturas giram em torno de $24^{\circ}$ a $26^{\circ} \mathrm{C}$, com duas estações definidas e índices pluviométricos reduzidos. A geodiversidade presente no Baixo Parnaíba Maranhense apresenta uma variedade de ecossistemas em estado de conservação, baixo impacto ambiental e percursos pouco acidentados. O conjunto destes fatores favorece o desenvolvimento de roteiros cicloturísticos.

Além disto, cumpre ressaltar a existência de uma demanda crescente de ciclistas/cicloturistas e que pode ser cooptada, em longo prazo, para a realização de roteiros integrados de excursionismo no meio rural. Trata-se de uma realidade vigente e que começa a desbravar as zonas rurais do município de São Bernardo com o objetivo de estabelecer uma maior proximidade dos visitantes com as paisagens locais. O cicloturismo refere-se a um modo particular de vivenciar o espaço, como uma maneira saudável, econômica e ecológica de se fazer turismo (LIMA, 2015).

Os eventos esportivos organizados pelos órgãos públicos em parceria com a comunidade tendem a fomentar ações de/para o cicloturismo, dinamizando também a economia local por meio da venda de acessórios, equipamentos, alimentos e bebidas e material de apoio ao desenvolvimento desta atividade. Rotas cicloturísticas, como por exemplo, a Rota Caldo de Cana, Trilha Racha Coco e Rally do Sol impulsionam a 
valorização dos povoados do Baixo Parnaíba Maranhense, ao tempo em que atraem um público significativo de participantes e espectadores (Figuras 3 a 5).

FIGURA 3- CICLOTURISMO NA ZONA RURAL DE SÃO BERNARDO

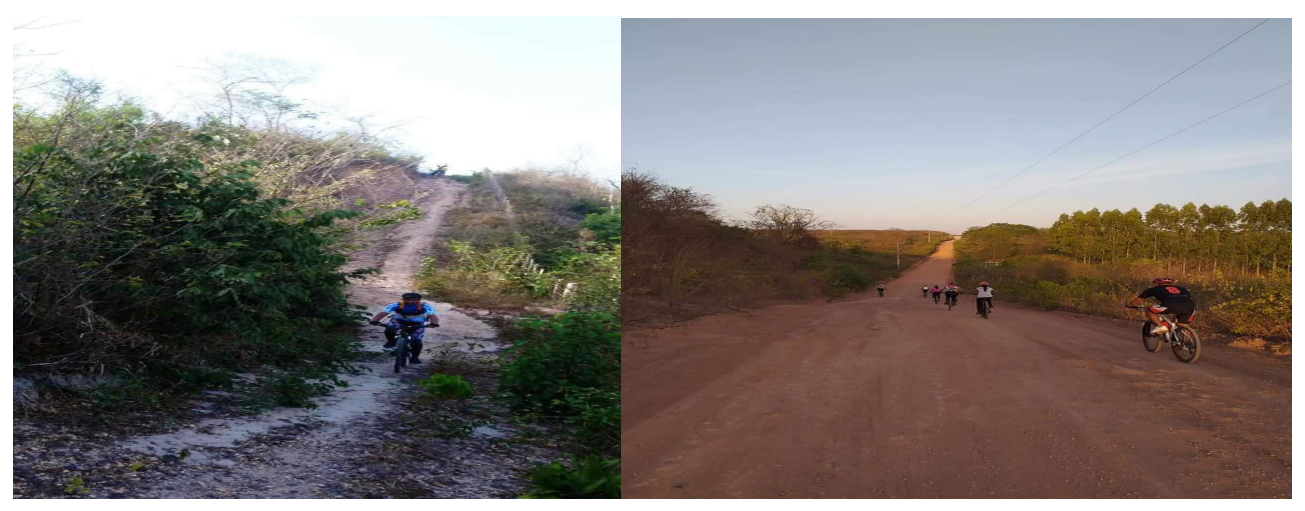

FONTE: Grupo Pedal Livre (2019).

FIGURA 4- ATRATIVOS TURÍSTICOS AO LONGO DO PERCURSO DA ROTA CALDO DE CANA

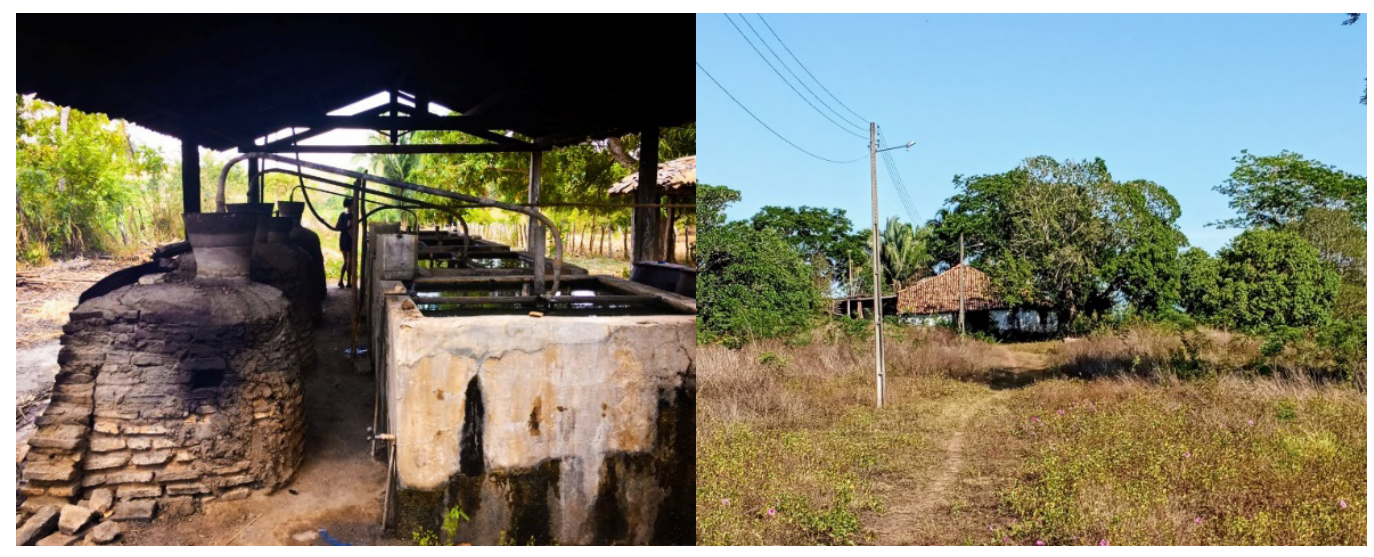

FONTE: Gomes (2019). 
FIGURA 5- ESTRUTURA DE APOIO MONTADA DURANTE OS EVENTOS DE CICLOTURISMO

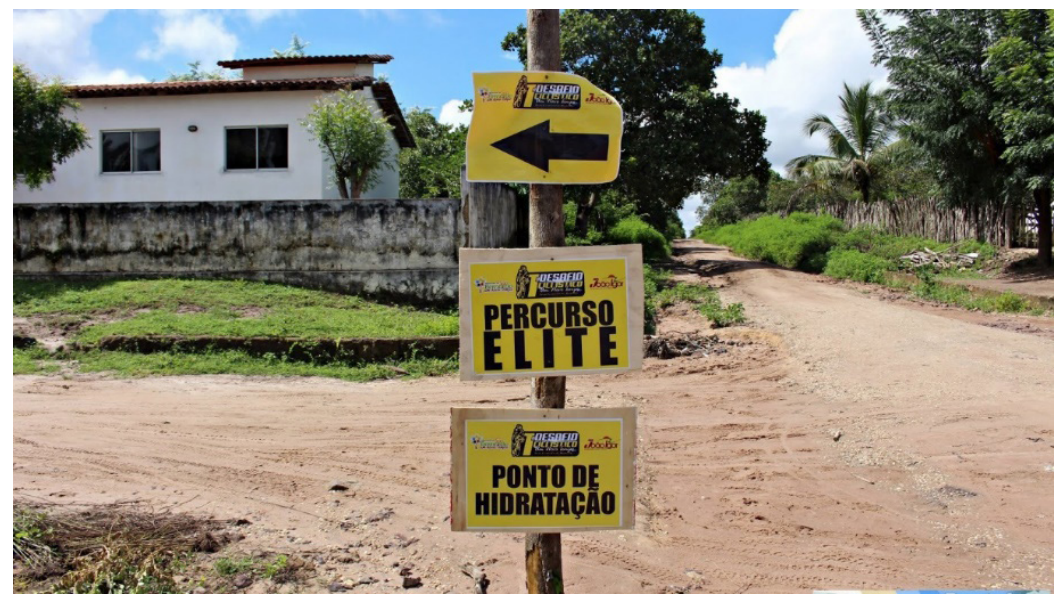

FONTE: Grupo Pedal Livre (2019).

Os roteiros e rotas cicloturísticos não apresentam um nível elevado de dificuldade técnica e elevações significativas no terreno; não há tráfego excessivo de veículos e os atrativos naturais e históricos encontram-se conservados, configurando uma atividade propícia à contemplação. Os visitantes percorrem estradas de terra caracterizadas por elementos típicos do meio rural: paisagens campestres, plantações de pequenos agricultores, produção artesanal, gastronomia, além de remanescentes do período colonial, como por exemplo, casas de farinha e antigos engenhos de canade-açúcar. Durante os eventos ciclísticos, os gestores públicos em parceria com a iniciativa privada disponibilizam uma infraestrutura de equipamentos e serviços, tais como sinalização e pontos de apoio, com o intuito de propiciar o acolhimento aos participantes e ao público espectador.

As práticas de cicloturismo tem conferido visibilidade aos locais onde os percursos se desenvolvem e, consequentemente, aos patrimônios ambientais e culturais presentes no meio rural. Os ciclistas da cidade e de municípios vizinhos aproximam-se deste ambiente material e simbólico, com os elementos que configuram a paisagem natural (plantações, árvores frutíferas, rios) e os bens culturais representados pelos modos de vida, processos de produção, antigos engenhos.

Os roteiros desenvolvidos criam uma ambiência favorável às práticas de sociabilidade entre os visitantes e residentes dos povoados e de valorização das memórias e das histórias desses lugares: "[...] A transformação de uma memória coletiva em um produto [...], gera emprego, renda e autoestima, transformando aquela memória da falência e do abandono em lembranças de riqueza, aventura e fantasia (LIMA, 2015, p.122). 
Ao mesmo tempo, o cicloturismo em São Bernardo amplia o olhar sobre a zona rural, com possiblidades de organização de produtos e serviços voltados para suprir as necessidades desses visitantes. Conforme analisado, os cicloturistas possuem o interesse de vivenciar o meio ambiente e o patrimônio material e simbólico das comunidades, atrelando a educação ambiental e o lazer.

Em longo prazo, as rotas de cicloturismo podem se constituir alternativas para os pequenos agricultores, diversificando as suas atividades produtivas e incrementando a renda familiar com a inclusão social em negócios comunitários relacionados à hospedagem, gastronomia e à economia produtiva da bicicleta.

No entanto, o destino cicloturístico deve reunir condições estruturais e recursos humanos qualificados para dinamizar os setores relacionados ao turismo e à hospitalidade. Dentre elas, Saldanha (2017) enfatiza a existência de uma infraestrutura básica, atrativos naturais e culturais conservados, qualificação profissional, e serviços de apoio e complementares à visitação turística.

O envolvimento entre os gestores públicos, empresariado e comunidade local constitui fator primordial para que a prática do cicloturismo desenvolva-se em atenção às normativas deste segmento e possa ser considerado um destino turístico atrativo. Além destas ações, destacam-se a necessidade de criação de um órgão municipal de turismo, ações de qualificação profisisonal para a formação de guias de turismo e condutores ecológicos, realização de eventos técnicos e científicos, captação de eventos de caráter esportivo e cultural, organização de arranjos produtivos locais, com vistas a dar autonomia para as comunidades que residem nos povoados.

Dessa forma, o cicloturismo tende a ser uma prática capaz de viabilizar a inserção dos moradores dos povoados em atividades associadas ao turismo rural, ecológico e de lazer, valorizando as singularidades territoriais e o patrimônio imaterial dessas comunidades. Busca-se, então, promover o desenvolvimento rural integrado e em bases sustentáveis.

\section{CONSIDERAÇÕES FINAIS}

A argumentação desenvolvida nesse artigo buscou uma reflexão em torno da prática do cicloturismo no município de São Bernardo, no estado do Maranhão, como fator de valorização do meio rural e fortalecimento da atividade turística em vias de expansão. As práticas turísticas em áreas naturais são fortalecidas diante de um novo perfil de visitantes que busca maior interação com o meio ambiente e a comunidade local.

Nesse sentido, a segmentação de mercado caracteriza-se como uma estratégia de organização do setor turístico e valorização das singularidades dos destinos. Isto impulsiona o consumo de experiências em áreas naturais sob uma gama de interesses: turismo de aventura, turismo rural, turismo ecológico. O turismo de aventura e o turismo rural são considerados segmentos que aliam a conservação dos atrativos com possibilidades de interação entre os turistas, as paisagens e o cotidiano das 
comunidades. No âmbito destes segmentos turísticos, a prática cicloturística contribui para o processo de valorização dos atrativos naturais e culturais, ressignificando as paisagens por meio de uma vivência interpretativa dos lugares.

O cicloturismo é uma atividade que utiliza a bicicleta não apenas como meio de transporte sustentável e de baixo impacto ambiental. Configura-se como possibilidade de construção de uma experiência turística voltada para a valorização das paisagens rurais e urbanas, educação ambiental, bem-estar físico e psicológico dos visitantes. No tocante aos moradores das localidades turísticas, a relação entre meio ambiente e cicloturismo revela-se como oportunidade econômica, em virtude da necessidade de infraestrutura básica, equipamentos e serviços de apoio para viabilizar os roteiros, trilhas e eventos cicloturísticos.

Tal cenário foi problematizado no município de São Bernardo, Maranhão, onde evidencia-se um aumento da demanda pelo uso da bicicleta para fins utilitários e turísticos, com a realização de eventos e o surgimento de roteiros de cicloturismo na zona rural. Tendo em vista que o município não possui uma oferta turística estruturada, faz-se necessário pensar em alternativas voltadas à organização de serviços para viabilizar práticas turísticas e/ou excursionistas a partir das potencialidades e dos atrativos turísticos locais.

Nesse norte, constatou-se que as rotas de cicloturismo organizam a oferta de atrativos turísticos, conferindo visibilidade às produções materiais e simbólicas de uma comunidade, seus saberes e fazeres locais. No município de São Bernardo, Maranhão, as rotas suscitam experiências de lazer, aventura e contato com as paisagens e as comunidades. Dentre os benefícios verificados, destacam-se os processos de apropriação e valorização turística dos povoados rurais; roteiros e trilhas de cicloturismo revalorizam os patrimônios desses locais, a realização de eventos esportivos movimenta a economia e produz novos sentidos ao meio rural do Baixo Parnaíba.

A partir deste cenário, a pesquisa possibilitou uma análise acerca desta atividade, apontando algumas estratégias para que a localidade se torne um destino de cicloturismo atrativo e possa se inserir como destino indutor no Território do Baixo Parnaíba Maranhense. Constatou-se que existe uma demanda de consumo das áreas naturais sob a forma de excursionismo, tanto por parte dos residentes, como por parte de visitantes em nível regional. O município possui atrativos turísticos potenciais, sobretudo nos povoados que ainda guardam elementos de ruralidade $e$ que podem se converter em fatores de atratividade turística em longo prazo.

A articulação entre comunidade, governo e iniciativa privada emerge como premissa essencial para que o turismo possa se materializar de modo harmônico no meio ambiente. Há a necessidade de articular ações em prol do turismo local: alocação de infraestrutura básica e turística, serviços de apoio ao turismo, estudos de mercado para definir os segmentos prioritários do destino, dentre outras iniciativas.

Atrelado ao planejamento do turismo, há a necessidade de identificar novas rotas de cicloturismo na região, estruturando roteiros em parceria com o empresariado 
local e moradores, de modo a estimular segmentos de mercado, como o turismo de aventura e o turismo rural.

Os resultados obtidos refletem apenas uma dimensão cicloturismo, com um olhar voltado para as experiências de interpretação e de valorização do meio rural que a sua prática poderá suscitar. Dentre as limitações da pesquisa, destaca-se a não caracterização do perfil socioeconômico dos ciclistas/cicloturistas e das suas percepções, sendo assim, sugerem-se investigações acerca essas temáticas. As análises relacionadas à estruturação e gestão dos roteiros e às políticas públicas locais de incentivo ao cicloturismo são algumas vertentes que poderão ser alvo de futuras abordagens.

Com base na discussão teórica e do cenário empírico observado no município de São Bernardo, o cicloturismo pode ser uma alternativa viável para iniciar o processo de valorização do lugar, suas memórias e paisagens, e, consequentemente, ancorar perspectivas de desenvolvimento em bases locais.

\section{REFERÊNCIAS}

AGUILAR, V.; RIVAS, H.; GONZALEZ, R. Glossário de términos técnicos relacionados com la actividad turística habitualmente empleados em Chile. Boletin Turistico, Santiago, n.1, p.1-67, 2008. Disponível em: <https://issuu.com/issuesoto/ docs/glosario_de_turismo_sernatur>. Acesso em: 12 abr. 2020.

ARENHART, A.; FONTANA, R. de F. Reflexões sobre o Turismo Rural e o Desenvolvimento Sustentável. Turismo e Sociedade. Curitiba, v. 12, n. 3, p. 139157, setembro-dezembro de 2019, p. 139-157.

BOTELHO, A. C. Resistência camponesa entre chapadas, carrascos e matos no Baixo Parnaíba, Maranhão. 158 f. Dissertação (Mestrado em Geografia), Universidade Federal do Ceará, Fortaleza, 2017.

CARVALHO, T.J. L.; RAMOS, J.L.; SYDOW, E. O cicloturismo como fator de desenvolvimento da atividade turística nas cidades de Araguaína e Nova Olinda (TO). Revista Brasileira de Ecoturismo, v.6, n.4, p.63-82, 2013.

CARVALHO, M.S.; MOESCH, M.M. Turismo como fenômeno social e suas implicações no espaço rural. Revista Brasileira de Ecoturismo. São Paulo, v.6, n.2, p.442-457, 2013.

CARVALHO, C. Q. R. Planeamento da Rota Cicloturística EuroVelo 3 - Rota dos Peregrinos em Portugal. Construção de um modelo SIG baseado na optimização de percursos e no apoio à decisão. 113 f. Dissertação (Mestrado em Arquitectura Paisagista), Instituto Superior de Agronomia, Universidade de Lisboa, Lisboa, 2017. 
COSTA, S. B. Chapadas e lutas: resistência camponesa no Baixo Parnaíba Maranhense na rota do agronegócio silvicultor - conflitos territoriais e "usos" da natureza. 194 f. Tese (Doutorado em Geografia), Universidade Federal de Pernambuco, Recife, 2016.

CERVO, A. L. Metodologia científica. São Paulo: Pearson Prentice Hall, 2007.

DE OLIVEIRA NEVES, J. M; ESPERANÇA, J. P. Bike usage and cycle tourism: the pattern of portuguese associated bike riders. Tourism \& Management Studies, v.1, p. 191-200. Universidade do Algarve Faro, Portugal, 2011.

DEENIHEM, G.; CAULFIELD, B. Do tourist value different levels of cycling infrastructure? Tourism Management. Elsevier. n. 46, 2015.

DENZIN, N. K; LINCOLIN, Y. S. O planejamento da pesquisa qualitativa: teorias e abordagens. Tradução Sandra Regina Netz. 2ed. Porto Alegre: Artmed, 2006.

FARIAS, G. R. de. O Cicloturismo como experiência turística. 87 f. Monografia (Bacharelado em Turismo), Instituto de Ciências Humanas e Sociais, Novo Hamburgo, Rio Grande do Sul, 2019.

FIALHO, A. R.; EUSEBIO, C.; Motivations and travel behavior of cycling tourists: a youth Market analysis. Revista Turismo \& Desenvolvimento. n. 7/28, p. 20732084, 2017.

FLORES, R.; RAMIRO, A.; TADDIA, A. P.; PARDO, C. F.; LLERAS, N. Ciclo-inclusión en América Latina y el Caribe: Guia para impulsar el uso de la bicicleta, 2015.

GARCÊS, P. da S. Os observatórios de turismo como instrumentos de planejamento e gestão dos destinos: uma proposta de implantação para o município de São Bernardo - MA. 72 f. Trabalho de Conclusão de Curso (Curso de Bacharelado em Turismo), Universidade Federal do Maranhão - UFMA. São Bernardo, 2019.

GIL, A. C. Como elaborar projetos de pesquisa. São Paulo: Atlas, 2002.

GOMES, J. G. Educação Patrimonial e Turismo Cultural: um projeto de conscientização, valorização e manutenção da história e memória do povoado São Raimundo.111f. Trabalho de Conclusão de Curso (Curso de Bacharelado em Turismo), Universidade Federal do Maranhão-UFMA. São Bernardo, 2019.

GRUPO PEDAL LIVRE. Acervo fotográfico. São Bernardo, 2019.

HANDY, S.; VAN WEE, B.; KROESEN, M. Promoting Cycling for Transport: Research Needs and Challenges. Transport Reviews, 34, v.1, p.4-24, 2014. 
HAN, H.; MENG, B.; KIM, W. Bike-traveling as a growing phenomenon: Role of attributes, value, satisfaction, desire, and gender in developing loyalty. Tourism Management. v. 59, p. 91-103, 2017.

INSTITUTO BRASILEIRO DE GEOGRAFIA E ESTATÍSTICA (IBGE). Panorama das cidades brasileiras (2010). Disponível em: <https://cidades.ibge.gov.br/brasil/ma/ sao-bernardo/historico>. Acesso em 17 ago. 2020.

IRVING, M.; AZEVEDO, J. Turismo: o desafio da sustentabilidade. São Paulo: Futura, 2002.

KLOS, R. C.; MISKALO-CRUZ, M.; MORAES, L. Espaço e Cicloturismo: a representação urbano-turística de Curitiba/PR em fotografias postadas no Tripadvisor. Marketing \& Tourism Review. v. 1, n. 2, p. 1-30, 2016.

LIMA, B. L. Estrada Geral do Sertão: potenciais turísticos de um caminho quase esquecido. 159 f. Dissertação (Mestrado Profissional em Turismo), Universidade de Brasília, Brasília, 2015.

LAMONT, M. Reinventing the Wheel: A Definitional Discussion of Bicycle. Journal of Sport \& Tourism. v. 14, n.1, p. 5-23, 2009.

LANZILLOTTA, A. de S. Cicloturismo: por uma diversificação do turismo realizado na cidade do Rio de Janeiro. 89 f. Monografia (Bacharelado em Turismo) Faculdade de Turismo e Hotelaria, Universidade Federal Fluminense, Niterói, 2013.

MENDONÇA, J. Desafios, oportunidades e recomendações para o fomento ao cicloturismo nas costas do cacau e descobrimento - Sul da Bahia. $102 \mathrm{f}$. Dissertação (Mestrado em Conservação da Biodiversidade e Desenvolvimento Sustentável), Escola Superior de Conservação Ambiental e Sustentabilidade), Nazaré Paulista, 2017.

MINISTÉRIO DO DESENVOLVIMENTO AGRÁRIO (MDA). Secretaria de Desenvolvimento Territorial (SDT). Território Baixo Parnaíba. Plano territorial de Desenvolvimento rural sustentável. São Luís, 2005.

MRNJAVAC, E., KOVACIC, N., TOPOLSEK, D. The logistic product of bicycle destinations. Tourism and Hospitality Management, n.20, v.2, p.171-184, 2014.

OLIVEIRA, V. S. de; ANUNCIAÇÃO, V. S. A arte do novo segmento turístico: Cicloturismo In: Revista Pantaneira, Aquidauana, MS, v. 5, n. 1, jan./jun, p. 44-51, 2003. 
OLIVEIRA, R. R. de. Devagar quase parando: o uso da bicicleta como ferramenta para o estudo da paisagem. In: Oliveira, R. R. de; RUIZ, A. E. (Orgs.). Geografia histórica do café. Rio de Janeiro: Ed. PUC-Rio, p.37-60, 2018.

RITCHIE, B. W. Bycicle tourism in the South island. Of new zealand: planning and management issues. Tourism Management, v. 19, n. 6, p. 567-582, 1998.

ROLDAN, T. R. R. Cicloturismo: planejamento e treinamento. 43 f. Monografia (Bacharelado em Educação Física, modalidade Treinamento em Esportes) Faculdade de Educação Física, Universidade de Campinas, Campinas, 2000.

ROSA, A. C.; SILVA, J. F. da. Políticas Públicas e Cicloturismo: uma análise comparativa entre Piraquara (Brasil) e Eisenstadt (Áustria). Turismo e Sociedade. Curitiba, v. 13, n. 2, p. 44-63, 2020.

RUFINO, B.; CRISPIM, M.C. Cicloturismo: uma alternativa de transporte turístico sustentável para a cidade de João Pessoa, Paraíba. In: CONGRESSO BRASILEIRO DE GESTÃO AMBIENTAL E SUSTENTABILIDADE, 2015. Anais...., João Pessoa: Ego Gestão Brasil, 2015. Disponível em: <http://eventos.ecogestaobrasil.net/congestas/ >. Acesso em 22.05.2020.

SALDANHA, L. E. da C. Políticas cicloinclusivas e cicloturismo: o caso do Rio de Janeiro/RJ. 107 f. Dissertação (Mestrado em Engenharia dos Transportes), Universidade Federal do Rio de Janeiro, Rio de Janeiro, 2017.

SERRA i SERRA, M. El cicloturismo y las vías verdes como ejemplo de turismo sostenible. Revista CIDOB d'Afers Internacionals, v. 113, p. 187-209, 2016.

SERRANO, C.; CESAR, L. F.; DO PRADO, M. C. Cicloturismo: mobilidade, estilo de vida e experiência. In: PANOSSO NETTO, A.; ANSARAH, M.G dos R.

Produtos Turísticos e novos segmentos de mercado: planejamento, criação e comercialização. São Paulo: Manole, 2015.

SOARES, A. Circuitos de Cicloturismo: manual de incentivo e orientação para os municípios brasileiros. Via Ciclo: Florianópolis, 2010.

SOUSA, R. de O.; PINTO, E. R.; JÚNIOR, C. C.de M. "Agosto em festa se enfeita”: religiosidade, práticas devocionais e representações simbólicas no Festejo de São Bernardo - MA. In: Revista Interdisciplinar em Cultura e Sociedade (RICS). v. 4, p. 495-516, 2018.

SOUZA, F. H. P. de. O ciclismo como incremento do turismo em Fortaleza:

propostas de cicloturismo. 231 f. Dissertação (Mestrado Profissional em Gestão de Negócios Turísticos) - Centro de Estudos Sociais Aplicados, Universidade Estadual do Ceará, Fortaleza, 2019. 
TEIXEIRA, C. A.; EDRA, F. P. M. Bicicleta no planejamento urbano e nas estratégias: um aproveitamento para o turismo. Revista Turismo e Desenvolvimento, Aveiro, 1 (30), p. 37-49, 2018.

UVINHA. R. R. Turismo de Aventura: reflexões e tendências. São Paulo: Aleph, 2006.

Recebido em: 21-04-2020

Aprovado em: 27-03-2021 
$S$ 